\title{
Relevance of Database and Information Retrieval System in Mechanical Engineering Program: A Case Study
}

\author{
Chithra Biju Menon, Vaibhav Narwane \\ Mechanical Department, K.J. Somaiya College of Engineering, Vidyavihar, Mumbai -400077 ,India \\ chitramenon@somaiya.edu, vsnarwane@somaiya.edu
}

\begin{abstract}
:
A mechanical engineer often experiences the need for working on databases in his career. However, it is observed that there is difficulty in convincing the students of Mechanical Engineering Program that the course of Database and Information Retrieval System is relevant to them. This paper focuses on the methodology adopted in order to reinforce the belief in the course of database and information retrieval system. It discusses about the objectives that were framed for the same. In order to attain the objectives, the students were trained to use Visual Basic for creating graphical user interface and SQL for making databases. The students were instructed to make applications related to mechanical engineering in groups of four. The feedbacks were taken from the students after the course. The qualitative analysis on the feedbacks from the students indicates that the students are able to create applications related to mechanical engineering. Validation was done using practical examination results of same batch of students. The performance of the students in the end semester practical exam also makes it evident that the students are comfortable in making User interface and database for any given application.
\end{abstract}

Keywords: Database and Information Retrieval System, Graphical User Interface, mechanical engineering

\section{Introduction}

The main focus of mechanical engineering field is to develop and manufacture a product (Beuren et al., 2013). It involves a number of manufacturing processes. A large amount of dependent and independent data is involved at each stage of manufacturing a product. It is very important to have a consistent data that is readily available at the various stages which is possible by the use of database management systems (DBMS) (Liu and $\mathrm{Xu}, 2001$ ). The data can be used by multiple application programs used in the manufacturing processes (Hardell et al., 1995). The database management system has to store data related to the product design, manufacturing, assembly, testing and maintenance (Hameri and Nikkola, 1999). Thus it is very essential for the students of the mechanical branch to have a basic understanding of the database management systems (Shah et al., 1996). There are certain biased thoughts in the students that are admitted to the mechanical engineering program. They believe that the courses that will be offered to them will be limited to the ones that have a flavour of mechanical, thermal and fluid design, manufacturing processes and the related management courses. As a result of this when they are introduced to the courses like $\mathrm{C}$ programing and courses on database management systems, there are always remarks like 'Oh $\mathrm{C}$, why me?', 'How am I related to data in any way? In order to overcome these types of reactions from the students, we, at K.J. Somaiya College of engineering tried to put some efforts to reinforce the belief of the students that the course 'Database Management and Information Retrieval System' is relevant and useful for mechanical engineers. Database and Information retrieval is a course that is offered to the third year students of the mechanical engineering program. It is a laboratory course with contact period of 1 hour of tutorial and 2 hours of practical. The credits assigned to the course are 2. The evaluation scheme is 50 marks of term work and practical exam of 50 marks. Out of the 50 marks that were allotted to the term work, 25 marks were allotted to the laboratory experiments and 25 marks for a mini project. The efforts to reinforce the belief that the course is relevant to the program are discussed here.

The objectives of the effort are as below:

Core research objective (RO): To reinforce the relevance of the course Database and Information Retrieval System in mechanical engineering program.

Sub objective1 (RO1): To develop an ability in students of mechanical engineering program to design database for mechanical engineering application.

Sub objective2 (RO2): To develop an ability in students of mechanical engineering program to develop GUI for mechanical engineering application.

To address above research objectives, programming language Visual Basic.net (VB.net) and database language Structured Query Language (SQL) were taken as tools for implementation (Bai, 2012). VB.net and SQL are popularly used in engineering applications (Yang, 2007). Practicals were conducted for VB, SQL, and interfacing VB with SQL. Case studies were given to group of students for implementation. In order to analyse the attainment of the above objectives, feedback has been collected from the students. The flow is represented in Fig. 1. 


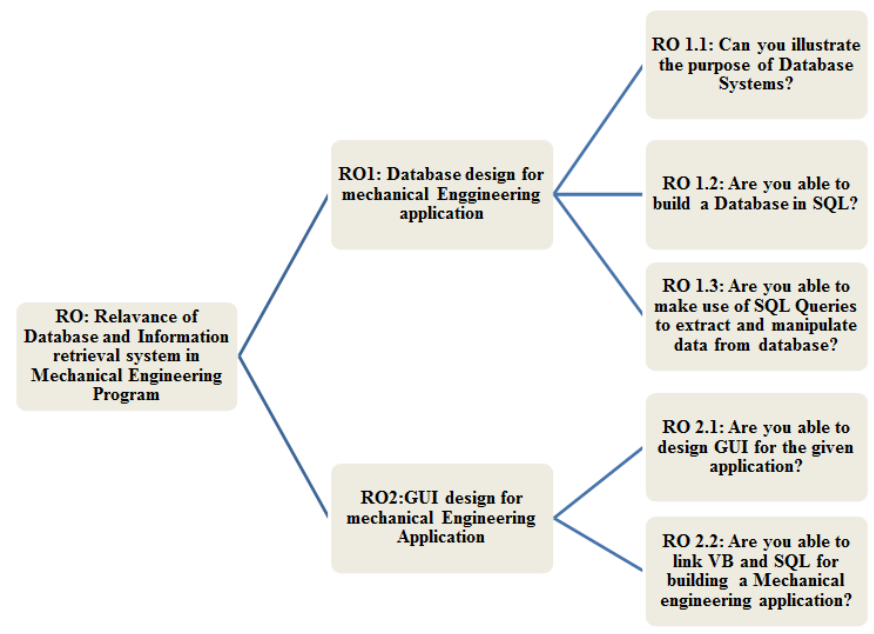

Fig. 1 Research Objectives

Organization of the paper is as follows: Section 2 describes the methodology adapted to address the research objectives. It includes the discussion on the training given to the students, formation of groups of students and execution of the project, project evaluation and feedback. The Section 3 gives the results and discussions on the feedback from the students. Validation of the same by considering the end semester practical examination is also discussed.

\section{Methodology}

In some of the earlier studies various authors have addressed the issue of lack of interest in computers, especially in developing and underdeveloped countries. Few of the important studies are as follows: Dasuki and Quaye (2016) conducted study in Nigeria, Boyeena and Goteti (2010) applied active learning technique through case study in database course. However these studies were not for mechanical engineering graduates. In order to induce a faith in the students that the course is useful to the mechanical engineering students the following methodologies were used:

\section{A. Training the students:}

The students are trained on SQL and VB .Net platform through 1 hour lecture session and 2 hours of practical sessions. In the lectures the concepts of database management systems and graphical user interface (GUI) is discussed. In the practical sessions there are total 6 experiments which comprises of exercises to be completed using SQL and VB .Net. These exercises give hands on experience of working on the software. They enable the students to learn the languages.

\section{B. Forming the groups of the students:}

The groups comprising of four students were formed. We chose 4 students since 4 is an ideal team size for small projects. 2-3 students will not give a feel of working in teams and having more than 4 students will dilute the contribution of each student in the project.

C. Project Execution:

Topic Selection: In the academic years 2016-17 and 201718 , every group was asked to select any topic related to mechanical engineering for the project.
In the year 2018-19, we floated areas that included Computer integrated manufacturing, Robotics, Smart factory, Sustainable practices, Assistive technology, Supply chain management, Additive manufacturing, CNC, Service sector, all of which are related to mechanical engineering field. Every student was asked to review research on the given areas. From the literature available they had to define problems in that area whose solution can be provided using database management system and graphical user interface. This gave them an opportunity to explore the various ways in which a mechanical engineer help provide a software solution to the problems specific to their areas.

Data modelling: Once their topic was finalised, they were asked to prepare an entity relationship model for the database requirements. This would ease their task of making the database.

Relational model: After the database model was ready, database was to be created for the application using SQL. Graphical User Interface creation: They were asked to create user interface for the application. This interface would perform the desired operations by interacting with the database.

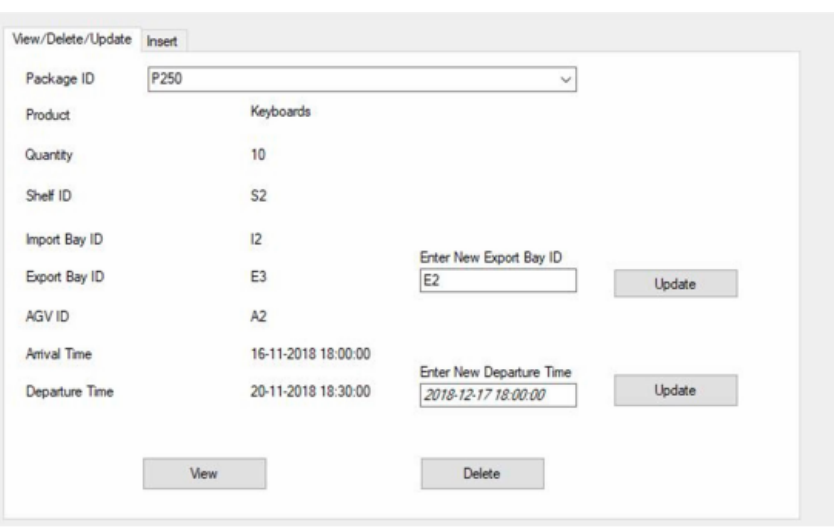

Fig. 2 Sample project on Smart factory (2018-19)

\section{Project Evaluation:}

The project was evaluated on the basis of the execution of the same. The problem definition, the database and the GUI that was created and the report were the criteria of evaluation of the project.

\section{E. Feedback:}

Feedbacks were taken from the students at the end of the course and the same was analysed for the attainment of the objectives.

\section{Case Illustration:}

The case considered here is of the academic year 20172018. The total number of student participants was 150 . The entire activity was distributed across a span of 15 weeks. The timeline chart of the various activities is illustrated in Fig. 3. In the first 4 weeks the concepts of DBMS and GUI were explained to the students. The mode of delivery was through 1 hour of lecture and 2 hours of 
practicals per week. In the lectures the basic purpose of database systems with GUI and the implementation of the same were discussed. In the practical sessions the students were given exercises in SQL and VB .Net to get hands on experience of working on the same. In the week number 5 , the groups were formed during the practical sessions. The participants were briefed about the activities. Week number 6 is allotted to literature review where the students get an idea of the various options available where a mechanical engineer can contribute through his knowledge of DBMS and GUI. This helps them to identify a problem and define it which is approved in the next week. Once their problem is approved, they are asked to prepare an ER model in the week no. 8 which forms the basis of the database. The layout of the user interface representation was then prepared in the week no. 9. The ER model and the GUI layout once approved, the students were asked to prepare the relational database in SQL in week no. 10. In the week no. 11 the students prepared the GUI forms using VB.Net. The codes were written in VB .Net for connecting the user interface with the database in week 12. Testing and rectification of errors was done week 13 . This activity was followed by report writing and presentation and submission in the weeks 14 and 15.

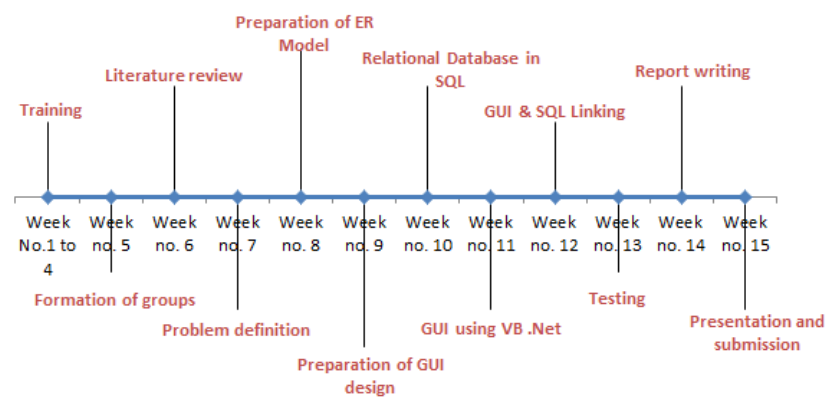

Fig. 3 Timeline of the project activities

Feedbacks were collected from the students by sharing the Google forms, the responses of which are available in Fig. 4. Likert scale with 1 to 5 was used for taking the responses (Albaum, 1997). 1 indicates minimum rating and 5 indicates maximum. There is no fixed rule for selection of Likert scale (Brooke, 1996). However, scale of 5 is most common (Boone and Boone, 2012). 1 indicates minimum rating and 5 indicates maximum. The feedback questions are mentioned in Fig. 1. The attainment of the objectives was calculated on the basis of the ratings.

\section{Can you illustrate the purpose of Database Systems?}
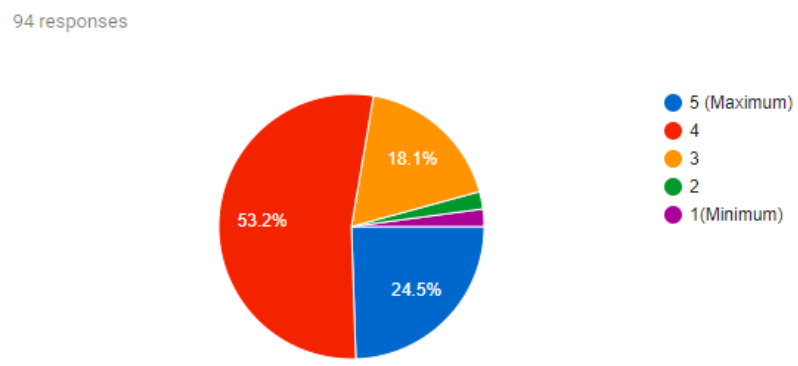

Are you able to build a Database in SQL?

94 responses
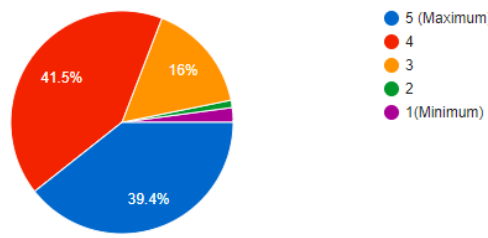

Are you able to make use of SQL Queries to extract and manipulate data from database?
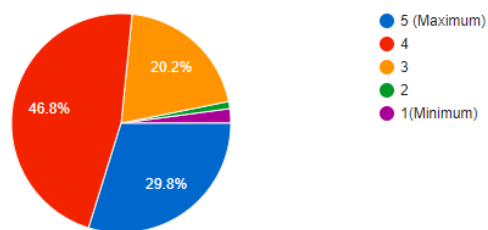

Are you able to design GUI for the given application? 94 responses
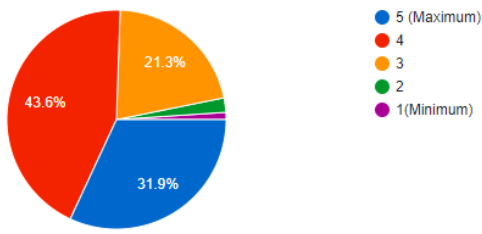

Are you able to link VB and SQL for building a Mechanical engineering application?
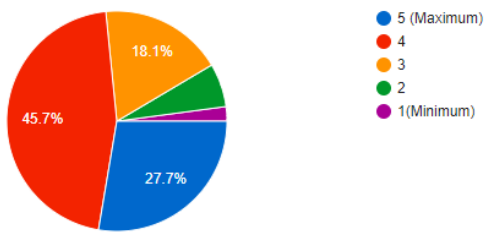

Fig. 4 Responses of the feedback questions (2017-18)

On same lines the study was carried out for 2016-17 and 2018-19. This study summarizes findings of these years.

\section{Results and Discussion}

In order to find out the level of attainment of the objectives the qualitative analysis was performed. The attainment is available for three academic years in Table 1. As per the feedback from the three years, it has been observed that the students are able to understand the purpose of database system and GUI for mechanical engineering applications and are capable of building software related to the same.

Table 1: Summary of Results

\begin{tabular}{|l|l|l|l|}
\hline \multirow{2}{*}{ RO } & \multicolumn{3}{|c|}{ Responses } \\
\cline { 2 - 4 } & $\mathbf{2 0 1 8 - 1 9}$ & $\mathbf{2 0 1 7 - 1 8}$ & $\mathbf{2 0 1 6 - 1 7}$ \\
\hline RO1.1 & 78.71 & 79.15 & 87.89 \\
\hline RO1.2 & 80.18 & 82.98 & 89.44 \\
\hline RO1.3 & 76.51 & 80.21 & 89.44 \\
\hline RO2.1 & 74.86 & 80.64 & 81.05 \\
\hline RO2.2 & 73.76 & 78.09 & 81.05 \\
\hline
\end{tabular}


The responses of these three years show consistently high achievement for ROs. Even though attainment is slightly reduced in 2018-19, it is still more than $70 \%$. Reasons for the reduction of the attainment are as follows: In initial years we have given very simple projects to students. However, the level of difficulty for projects was increased gradually. The attainment of $\mathrm{RO} 2.2$ indicates that the students are comfortable to make an application related to the mechanical Engineering stream which indicates that they find it relevant to their stream.

In order to validate the proposed method, the practical examination data of same sample of students was taken. The results of the same are given in Table 2. The statistical analysis of the practical examination shows the supporting evidence for the results shown in Table 1. In practical examination, there were two questions for each student. First question on SQL and second on VB. The mean, mode, and median values are in acceptable range for all three academic years. The standard deviation values are ranging from 1.35 to 4.29 , which could be because of variation in performance of few students.

Table 2. Results of Practical Examination

\begin{tabular}{|c|l|r|r|r|r|r|r|}
\hline \multirow{2}{*}{$\begin{array}{c}\text { Sr. } \\
\text { No }\end{array}$} & & \multicolumn{2}{|c|}{ SQL(Out of 25 marks) } & \multicolumn{2}{|c|}{ VB(Out of 15 Marks) } \\
\cline { 3 - 8 } & & $\begin{array}{c}\mathbf{2 0 1 8}- \\
\mathbf{1 9}\end{array}$ & $\begin{array}{c}\mathbf{2 0 1 7 -} \\
\mathbf{1 8}\end{array}$ & $\begin{array}{c}\mathbf{2 0 1 6 -} \\
\mathbf{1 7}\end{array}$ & $\begin{array}{c}\mathbf{2 0 1 8} \\
\mathbf{1 9}\end{array}$ & $\begin{array}{c}\mathbf{2 0 1 7} \\
\mathbf{1 8}\end{array}$ & $\begin{array}{c}\mathbf{2 0 1 6 -} \\
\mathbf{1 7}\end{array}$ \\
\hline $\mathbf{1}$ & $\begin{array}{l}\text { Sample } \\
\text { size }\end{array}$ & 158 & 148 & 155 & 158 & 148 & 155 \\
\hline $\mathbf{2}$ & Mean & 21.23 & 19.63 & 21.75 & 11.76 & 12.28 & 12.70 \\
\hline $\mathbf{3}$ & Mode & 22.00 & 21.00 & 23.00 & 12.00 & 13.00 & 13.00 \\
\hline $\mathbf{4}$ & $\begin{array}{l}\text { Media } \\
\text { n }\end{array}$ & 22.00 & 22.00 & 23.00 & 12.00 & 14.00 & 13.00 \\
\hline & $\begin{array}{l}\text { Standa } \\
\text { rd } \\
\text { Deviati } \\
\text { on }\end{array}$ & 2.48 & 4.29 & 2.14 & 2.09 & 2.50 & 1.35 \\
\hline
\end{tabular}

Thus the results obtained through course exit survey are validated for all three years.

\section{Conclusion}

It can be concluded that the activity has been proved useful for illustrating the relevance of Database management and information retrieval system to the mechanical engineering students. The students were able to identify problems related to their area and were able to provide solution for the same using SQL and VB .net. This activity gave them an opportunity to work in team for providing solutions. They defined timeline helped them to manage their time for planning and completing their activities.

The proposed analysis was validated with the practical examination results of the students.

Limitations of the study are as follows: Study was conducted in only one department, only three batches were analysed, and the scope of the study was for VB and SQL. In the future, a similar study can be conducted in disciplines for different subjects. However, findings of the study can be useful for academicians for policymaking regarding interdisciplinary courses in mechanical engineering.

\section{Acknowledgement}

We would like to acknowledge the continuous motivation and support from the management, Principal and department for implementing innovative teaching learning techniques. We would like to acknowledge the participation of all colleagues who has directly or indirectly contributed in the execution of the various activities related to it.

\section{References}

Albaum, G. (1997) The Likert scale revisited. Market Research Society. Journal., 39(2), 1-21.

Bai, Y. (2012) Practical database programming with Visual Basic. NET. John Wiley \& Sons.

Beuren, F. H., Ferreira, M. G. G. and Miguel, P. A. C. (2013) Product-service systems: a literature review on integrated products and services. Journal of cleaner production, 47, 222-231.

Boone, H. N. and Boone, D. A. (2012) Analyzing likert data. Journal of extension, 50(2), 1-5.

Boyeena, M. and Goteti, P. (2010, April) Promoting active learning through case driven approach: An empirical study on database course. In 2010 IEEE Students Technology Symposium (TechSym) (pp. 191-195). IEEE.

Brooke, J. (1996) SUS-A quick and dirty usability scale. Usability evaluation in industry, 189(194), 4-7

Dasuki, S. and Quaye, A. (2016) Undergraduate students' failure in programming courses in institutions of higher education in developing countries: A Nigerian perspective. The Electronic Journal of Information Systems in Developing Countries, 76(1), 1-18.

Hameri, A. P. and Nikkola, J. (1999) How engineering data management and system support the main process-oriented functions of a large-scale project. Production Planning \& Control, 10(5), 404-413.

Hardell, C., Stensson, A. and Jeppsson, P. (1995) A relational database for general mechanical systems. In Computational Dynamics in Multibody Systems (pp. 4959). Springer, Dordrecht.

Liu, D. T. and Xu, X. W. (2001) A review of web-based product data management systems. Computers in industry, 44(3), 251-262.

Shah, J. J., Jeon, D. K., Urban, S. D., Bliznakov, P. and Rogers, M. (1996) Database infrastructure for supporting engineering design histories. Computer-Aided Design, 28(5), 347-360.

Yang, M. S. L. (2007) SQL Server Data-Base Technology Based on VB [J]. Computer \& Telecommunication, 10 . 